\title{
Cerebral Glucose Metabolism Measured by Positron Emission Tomography in Term Newborn Infants with Hypoxic Ischemic Encephalopathy
}

\author{
KRISTINA THORNGREN-JERNECK, TOMAS OHLSSON, ANDERS SANDELL, \\ KJELL ERLANDSSON, SVEN-ERIK STRAND, ERIK RYDING, AND NILS W. SVENNINGSEN† \\ Departments of Pediatrics [K.T-J, N.W.S.], Radiation Physics [T.O., A.S., K.E., S-E.S.], and \\ Neurophysiology [E.R.], University Hospital, S-221 85 Lund, Sweden
}

\begin{abstract}
Total and regional cerebral glucose metabolism $(\mathrm{CMRgl})$ was measured by positron emission tomography with $2-\left({ }^{18} \mathrm{~F}\right)$ fluoro2-deoxy-D-glucose $\left({ }^{18} \mathrm{FDG}\right)$ in 20 term infants with hypoxic ischemic encephalopathy (HIE) after perinatal asphyxia. All infants had signs of perinatal distress, and 15 were severely acidotic at birth. Six infants developed mild HIE, twelve moderate HIE, and two severe HIE during their first days of life. The positron emission tomographic scans were performed at 4-24 d of age (median, $11 \mathrm{~d}$ ). One hour before scanning, 2-3.7 MBq/kg $(54-100 \mu \mathrm{Ci} / \mathrm{kg}){ }^{18} \mathrm{FDG}$ was injected i.v. No sedation was used. Quantification of CMRgl was based on a new method employing the glucose metabolism of the erythrocytes, requiring only one blood sample. In all infants, the most metabolically active brain areas were the deep subcortical parts, thalamus, basal ganglia, and sensorimotor cortex. Frontal, temporal, and parietal cortex were less metabolically active in all infants. Total CMRgl was inversely correlated with the severity of HIE $(p<0.01)$. Six infants with mild HIE had a mean (range) CMRgl of 55.5 (37.7-100.8) $\mu \mathrm{mol} \cdot \mathrm{min}^{-1} \cdot 100 \mathrm{~g}^{-1}, 11$ with moderate HIE had 26.6 (13.0-65.1) $\mu \mathrm{mol} \cdot \mathrm{min}^{-1} \cdot 100 \mathrm{~g}^{-1}$, and two with severe HIE had 10.4 and $15.0 \mu \mathrm{mol} \cdot \mathrm{min}^{-1} \cdot 100 \mathrm{~g}^{-1}$, respectively. Five of six
\end{abstract}

ABSTRACT

infants who developed cerebral palsy had a mean (range) CMRgl of $18.1(10.2-31.4) \mu \mathrm{mol} \cdot \mathrm{min}^{-1} \cdot 100 \mathrm{~g}^{-1}$ compared with 41.5 (13.0-100.8) $\mu \mathrm{mol} \cdot \mathrm{min}^{-1} \cdot 100 \mathrm{~g}^{-1}$ in the infants with no neurologic sequela at $2 \mathrm{y}$. We conclude that $\mathrm{CMRgl}$ measured during the subacute period after perinatal asphyxia in term infants is highly correlated with the severity of HIE and short-term outcome. (Pediatr Res 49: 495-501, 2001)
Bglc, blood glucose concentration
CMRgl, cerebral metabolic rate of glucose
CP, cerebral palsy
FDG, fluoro-deoxyglucose
GA, gestational age
HIE, hypoxic ischemic encephalopathy
LC, lumped constant
LCMRgl, local cerebral metabolic rate of glucose
PET, positron emission tomography
ROI, region of interest
SUV, standardized uptake value

Birth asphyxia among term infants remains a considerable problem in perinatal medicine with high rates of mortality and handicap (1-4). The clinical grading of HIE after perinatal asphyxia has become a useful prognostic tool in the term infant (5-7). Mild HIE usually results in a normal outcome and severe HIE in either death or CP. However, moderate HIE can result in either $\mathrm{CP}$ or a normal outcome (8). Early prediction of

Received January 10, 2000; accepted December 13, 2000

Correspondence and reprint requests: Kristina Thorngren-Jerneck, M.D., Department of Pediatrics, University Hospital, Lund University, SE-221 85 Lund, Sweden; e-mail: kristina.thorngren-jerneck@pedi.lu.se

Supported by grants from the Swedish Medical Research Council (Project No 4732), the Axel and Margaret Axelsson-Johnson Foundation, the Royal Physiographic Society, the First of May Flower Annual Foundation, the Linnéa and Josef Carlssons Foundation, the Sven Jerring Foundation, the Folke Bernadotte Foundation, and grants from Lund University Hospital.

$\dagger$ Deceased future handicap is important when selecting infants for early interventions, which may be possible in the near future $(9,10)$.

Several techniques have been used to investigate the cerebral pathology related to perinatal asphyxia. Cerebral morphology has been evaluated with computed tomography (CT) (11) and magnetic resonance imaging (MRI) $(12,13)$. Methods capable of detecting functional disturbances, such as phosphorus $\left({ }^{31} \mathrm{P}\right)$ magnetic resonance spectroscopy $(14)$ and proton $\left({ }^{1} \mathrm{H}\right)$ magnetic resonance spectroscopy (15), have been used to investigate changes in brain energy metabolism during the evolution of the secondary energy failure (16).

PET, measuring either cerebral blood flow (17) or CMRgl, has been used in a few studies on newborn infants. The first PET studies with FDG in newborn infants did not allow any quantification, making only relative values possible $(18,19)$. Phelps et al. (20) modified the Sokoloff et al. (21) method and 
replaced arterial blood samples with venous, which made it easier to quantify CMRgl also in children. However, CMRgl has been quantified by only a few investigators in newborn infants $(22,23)$ due to the required number of blood samples (20). In Finland, a semiquantitative analysis was used to measure SUV of glucose (24) and also an alternative method for quantification (25) when used for investigating CMRgl in early infancy. In the present study, we used a new method to quantify CMRgl with PET, based on the glucose metabolism of the erythrocytes (26).

The aim of the present study was to correlate cerebral glucose metabolism in the subacute period after asphyxia with the neurologic clinical scoring (HIE) of the term newborn infant after perinatal asphyxia and to quantify total and regional CMRgl in the neonatal brain. We also aimed to investigate the preliminary outcome of the infants and to correlate the CMRgl with the semiquantitative method, SUV multiplied by the glucose concentration in the blood (SUV $\times$ Bglc).

\section{MATERIAL AND METHODS}

Subjects. Twenty term infants born January 1995-April 1997 with HIE after birth asphyxia were investigated. The infants were treated in the neonatal intensive care unit at the University Hospital in Lund, Sweden, a tertiary-level neonatal unit. The following inclusion criteria were used: 1 , term newborn (gestational age $\geq 36 \mathrm{wk}$ ); 2, birth asphyxia: Apgar $<7$ at $5 \mathrm{~min} ; 3$, severe umbilical cord acidemia and/or late or prolonged decelerations on cardiotocography and/or placental abruptio; and 4, early postnatal signs of HIE (grade 1-3) (5). One infant with a 5-min Apgar 7 was included due to late decelerations on cardiotocography and moderate HIE for $7 \mathrm{~d}$ with seizures.

Nine infants were inborn and eleven were outborn and referred from hospitals within the southern region of Sweden during the first day of life. Clinical data on the infants are shown in Table 1. Fifteen of the 20 infants had a severe perinatal acidemia with a $\mathrm{pH}$ $<7.05 \mathrm{and} /$ or base excess $<-12 \mathrm{mmol} / \mathrm{L}$, measured in either umbilical cord blood (arterial or venous) or the umbilical catheters or capillary blood from the infant within $1 \mathrm{~h}$ after delivery. One infant was small for GA and two were large for GA (27). Eleven infants needed mechanical ventilation during the first days of life. Eight infants required dopamine treatment due to arterial hypotension (mean blood pressure $<30-35 \mathrm{~mm} \mathrm{Hg}$ ) on the first day of life. All infants had normal values of C-reactive protein the first day of life. Nine infants developed seizures, all within $24 \mathrm{~h}$ after birth. On the day of the PET scan, none of the infants had seizures, but three infants were still on treatment with antiepileptic drugs, two with phenobarbital and one with phenytoin. Two infants needed supplementary oxygen treatment on the day of the PET examination.

The present study was approved by the Research Ethics Committee and the Radiation Safety Committee at Lund University Hospital and by The Swedish Medical Products Agency. Informed consent was obtained from all parents.

Clinical scoring. All 20 infants were examined daily with clinical neurologic scoring for HIE according to Sarnat and Sarnat (5) for the three grades: 1, mild; 2, moderate; and 3, severe. Six infants developed HIE grade 1, twelve HIE grade 2, and two HIE grade 3 . The clinical neurologic condition of the infants with HIE grade 1 had on average normalized by postnatal d 3. In infants with HIE grade 2 and 3, clinical signs of HIE remained for 3-15 d. The infants were video recorded during the uptake period of FDG (during the injection and for 10-15 $\mathrm{min}$ ). The videotapes were later visually evaluated according to alertness and motor activity and the state of the infants divided into three categories, modified after Prechtl (28). The three categories were 1, quiet asleep, eyes closed; 2 , quiet awake, few movements, eyes open; and 3, awake, more movements, and/or crying.

PET scanning. PET scans were performed at postnatal age 4-24 d (median, 11 d). Twelve of the infants were investigated on $\mathrm{d} 8-12$. GA at the PET examination was $37-44 \mathrm{wk}$ (median, $41 \mathrm{wk}$ ). The PET scanner (PC384-7B, Scanditronix, Uppsala, Sweden) has four detector rings, generating four main and three cross-slices, thickness approximately $10-11 \mathrm{~mm}$. The sensitivity is $675 \mathrm{cps} / \mathrm{kBq} / \mathrm{mL}$ for the main slices and $945 \mathrm{cps} / \mathrm{kBq} / \mathrm{mL}$ for the cross-slices, and the spatial resolution

Table 1. Clinical characteristics of the infants*

\begin{tabular}{|c|c|c|c|c|c|}
\hline & $\begin{array}{l}\text { All infants } \\
(n=20)\end{array}$ & $\begin{array}{l}\text { Mild HIE } \\
(n=6)\end{array}$ & $\begin{array}{l}\text { Moderate HIE } \\
\quad(n=12)\end{array}$ & $\begin{array}{l}\text { Severe HIE } \\
\quad(n=2)\end{array}$ & $p$ value $\dagger$ \\
\hline GA at birth, wk & $40(36-42)$ & $41(40-42)$ & $39(36-42)$ & $37 ; 42$ & NS \\
\hline Birth weight, kg & $3.5(2.2-4.8)$ & $3.7(3.5-4.3)$ & $3.4(2.2-4.8)$ & $2.9 ; 4.2$ & NS \\
\hline \multicolumn{6}{|l|}{ Mode of delivery } \\
\hline Vaginal/cesarean section, $n$ & $11 / 9$ & $3 / 3$ & $7 / 5$ & $1 / 1$ & \\
\hline Lowest perinatal $\mathrm{pH}+$ & $6.95(6.68-7.25)$ & $6.98(6.68-7.25)$ & $6.96(6.70-7.18)$ & $6.81 ; 6.85$ & NS \\
\hline Lowest perinatal base excess $(\mathrm{BE}) \S \mathrm{mmol} / \mathrm{L}$ & $-20.2(-29--5)$ & $-20(-27--5)$ & $-19.6(-29--11)$ & $-26 ;-21$ & NS \\
\hline Apgar 5-min median (range) & $4(2-7)$ & $4.5(3-6)$ & $4(2-7)$ & $2 ; 3$ & NS \\
\hline Apgar 10-min median (range) & $6(4-8)$ & $6.5(4-8)$ & $6(4-8)$ & $4 ; 4$ & NS \\
\hline Mechanical ventilation, $n$ & 11 & 0 & 9 & 2 & \\
\hline Arterial hypotension, $n n$ & 8 & 0 & 6 & 2 & \\
\hline Seizures, $n$ & 9 & 0 & 7 & 2 & \\
\hline GA at PET, wk & $41(37-44)$ & $42(41-44)$ & $40(37-43)$ & 38 and 43 & \\
\hline
\end{tabular}

* Values are mean (range) unless indicated otherwise.

$\dagger$ Statistical method: 1-way ANOVA.

$\$ \mathrm{pH}$ in either cord blood or from the first hours of life, available in 17 infants (three missing in moderate HIE).

$\S \mathrm{BE}$ available in 16 infants (one missing in mild HIE and three missing in moderate HIE group).

I MABP $<30 \mathrm{~mm} \mathrm{Hg}$, treated with dopamine. 
is $7-8 \mathrm{~mm}$. The axial range is $81 \mathrm{~mm}$. We used an image matrix of $128 \times 128$ pixels with a pixel size of $2.2 \times 2.2 \mathrm{~mm}^{2}$. Corrections for random, scatter, and attenuation were done (29-31). Dead-time correction was also applied.

The $2-{ }^{18}$ FDG was synthesized by direct nucleophilic exchange on a quarternary 4 -aminopyridinium resin $(32) .{ }^{18} \mathrm{~F}$ was produced at the Lund electrostatic tandem accelerator with a proton beam of 6.0 MeV and produced by the ${ }^{18} \mathrm{O}(\mathrm{p}, \mathrm{n}){ }^{18} \mathrm{~F}$ reaction (33). The radiochemical purity of $2-{ }^{18} \mathrm{FDG}$ was better than $97 \%$.

Administration of $2-3.7 \mathrm{MBq}(50-100 \mu \mathrm{Ci})$ of ${ }^{18} \mathrm{FDG}$ per kilogram body weight was done during a 1-min injection into either a central or peripheral venous catheter. All infants had fasted for at least $2 \mathrm{~h}$ before the injection. Approximately $25 \mathrm{~min}$ after the injection, the infants were fed either by breast-feeding or bottle-feeding or by a nasogastric tube.

The infants were placed in a supine position on a warm water mattress $\left(37^{\circ} \mathrm{C}\right)$, and the head was positioned in the PET camera lightly fixed on a vac-pac containing polystyrene beads.

Most infants were asleep during the measurement. No sedation was used. During the PET scan, the infants were monitored clinically by a pediatrician and a neonatal nurse and, if necessary, with pulse oximetry. The PET scanning started approximately 60 min after FDG administration and consisted of two separate 10-min scans, in between which the couch was moved half a plane separation $(6.75 \mathrm{~mm})$ to get a higher axial sampling. CMRgl values were calculated using a modified autoradiographic formula based on the deoxyglucose model, which was also used by Rhodes et al. (34):

$$
\mathrm{MR}_{\mathrm{gl}}=\frac{\mathrm{C}_{\mathrm{gl}} \mathrm{C}_{\mathrm{i}}^{*}(\mathrm{~T})}{\mathrm{LC} \int_{0}^{\mathrm{T}} \mathrm{C}_{\mathrm{p}}^{*}(\mathrm{t}) \mathrm{dt}}
$$

where $\mathrm{MR}_{\mathrm{gl}}$ indicates metabolic rate of glucose, $\mathrm{C}_{\mathrm{gl}}$ is blood glucose, and $\mathrm{C}_{\mathrm{i}}^{*}$ is the amount of FDG-6-PO ${ }_{4}$ in an ROI. T is the time-point postinjection for the PET scan. The LC used for correction between the difference in metabolism of deoxyglucose and glucose is set to 0.52 for brain and assumed to be constant over time (35). $\mathrm{C}_{\mathrm{p}}^{*}(\mathrm{t}) \mathrm{dt}$ is the plasma concentration of FDG. To obtain the plasma integral of FDG, the erythrocytes were used as reference tissue (26). After the PET examination, one venous blood sample of $1 \mathrm{~mL}$ was drawn from the same catheter (possible in this method) used for the injection (26). The value of the integrated input function at the time for the PET scan to the sample time was calculated using a monoexponential function derived from a population-based venous blood curve (26). We also calculated the SUV, which has been used as a more simplified method, semiquantification. Using the SUV method, the Bglc during the PET has to be taken into account (36).

SUV

$=\frac{\text { Average concentration of radioactivity in a } \mathrm{ROI}(\mathrm{Bq} / \mathrm{ml})}{\text { Injected activity }(\mathrm{Bq}) / \text { body weight of infant }(\mathrm{g})}$
Radiation dosimetry. The absorbed dose was calculated according to the MIRD models based on the distribution data of Gallagher et al. (37), assuming a 1-h bladder-voiding interval. The bladder wall receives the highest absorbed dose, 0.8 $\mathrm{mGy} / \mathrm{MBq}$. The estimated effective whole-body dose equivalent was $0.16-0.17 \mathrm{mSv} / \mathrm{MBq}$.

Regional cerebral glucose metabolism. The acquired PET recordings of CMRgl were quantified by the use of ROI with a subdivision in anatomical regions based on an anatomical atlas (38). To match this anatomical atlas, the 14 brain slices from PET with $6.75-\mathrm{mm}$ spacing were converted to 10 slices with $\sim 10-\mathrm{mm}$ spacing, parallel to the orbitomeatal plane and starting at the orbitomeatal plane and continuing upwards. The ROI we chose were frontal, parietal, temporal, and occipital cortex, cerebellum, and subcortical gray matter (including basal ganglia and thalami).

Statistical analysis. The correlation between total mean CMRgl and the Sarnat and Sarnat (5) score was tested by the Kendall rank correlation and Kruskal-Wallis test. The results of the ROI analysis of the regional CMRgl distribution were submitted to a factor analysis (Varimax, oblique rotation) to redefine the ROI into a smaller number of functionally correlated factors to decrease the risk of mass significance at testing. The factor scores (relative CMRgl values) were then tested against the Sarnat and Sarnat (5) score by Kendall rank correlation test. Correlation between CMRgl and SUV $\times$ Bglc was tested by the Pearson correlation. Correlation of CMRgl with GA and outcome was evaluated with nonparametric tests (Spearman and Wilcoxon).

\section{RESULTS}

Total CMRgl decreased with increasing severity of HIE and was inversely correlated with the degree of $\operatorname{HIE~}(p=0.005)$ (Fig. 1 and Table 2). In all infants, the PET scan showed that the most metabolically active brain areas were the deep subcortical parts, thalamus, basal ganglia, and sensorimotor cor-

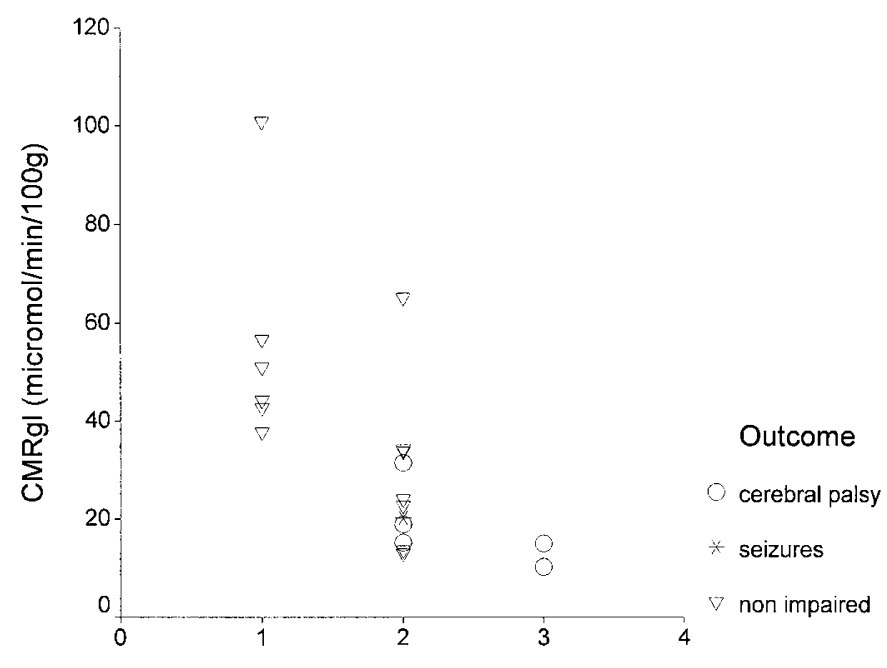

Hypoxic Ischemic Encephalopathy

Figure 1. Plot of CMRgl in 19 term infants according to the degree of HIE and outcome at 2 y of age. 1, mild HIE; 2, moderate HIE; 3, severe HIE. 
Table 2. Total and regional CMRgl and SUV multiplied by Bglc $(S U V \times B g l c)$ in 20 infants with HIE

\begin{tabular}{lcccc}
\hline & Mild HIE & \multicolumn{2}{c}{ Moderate HIE Severe HIE } & $p$ \\
& $(n=6)$ & $(n=12)$ & $(n=2)$ & value* \\
\hline CMRgl $(\mu \mathrm{mol} / \mathrm{min} / 100 \mathrm{~g}) \dagger$ & & & & \\
Whole brain & $55.5 / 47.6$ & $26.6 / 22.7$ & $10.2 ; 15.0$ & 0.005 \\
& $(37.7-100.8)$ & $(13.0-65.1)$ & & \\
Cerebellum & $55.5 / 50.6$ & $29.5 / 25.4$ & $10.9 ; 16.3$ & 0.006 \\
& $(39-97.5)$ & $(15.1-63.6)$ & & \\
Thalamus & $72.1 / 62.4$ & $32.1 / 33.5$ & $17.5 ; 27.4$ & 0.008 \\
& $(52.3-135.5)$ & $(13.7-74.4)$ & & \\
Frontal cortex & $53.9 / 47.4$ & $26.5 / 23.0$ & $9.8 ; 14.4$ & 0.006 \\
& $(37.3-97.8)$ & $(12.2-62.6)$ & & \\
\hline SUV $\times$ Bglc $(\mathrm{mmol} / \mathrm{L})$ & $5.7 / 5.7$ & $4.3 / 4.1$ & $2.0 ; 3.1$ & $<0.05$ \\
& $(3.6-7.6)$ & $(2.6-8.1)$ & & \\
\hline
\end{tabular}

Values are mean/median (range).

* Kruskal-Wallis test.

$\dagger$ CMRgl was not available from one infant with moderate HIE.

tex, whereas the cortical areas (frontal, parietal, and occipital regions) were less metabolically active (Fig. 2). There was a significant inverse correlation between the Sarnat score and the CMRgl also in the cerebellum, thalamus, and basal ganglia and the frontal cortex $(p<0.01)$ (Table 2). The regional CMRgl distribution obtained by the factor analysis contained two parts representing factor 1 , the subcortical parts and the temporal cortex, and factor 2 , the cortical parts of the brain. The regional $\mathrm{CMRgl}$ distribution did not correlate significantly with the clinical prognostic parameter (HIE). No region correlated significantly more than any other did in the method we used.

The SUV multiplied by the Bglc correlated significantly with the HIE grade $(p<0.05)$. There was a significant correlation between CMRgl and SUV $\times \operatorname{Bglc}(r=0.73, p<$ 0.01).

CMRgl increased with GA in all groups of HIE. Correcting for GA gave an even higher significance in the correlation between CMRgl and the HIE $(p=0.004)$. The global CMRgl correlated significantly with GA (weeks) at PET $(p<0.05)$ but not with the postnatal age (days) at PET $(p>0.2)$.

There was a significant correlation also between CMRgl and the outcome at $2 \mathrm{y}(p<0.05)$. The correlation of CMRgl with GA (weeks) and outcome is presented in Figure 3. At follow-up (2 y), all six infants with mild HIE were neurologically normal, but four infants with moderate HIE and the two with severe HIE developed CP. In five of the six infants with CP, quantitative values of CMRgl were obtained, with mean/ median (range) $18.1 / 15.2(10.2-31.4) \mu \mathrm{mol} \cdot \mathrm{min}^{-1} \cdot 100 \mathrm{~g}^{-1}$, to

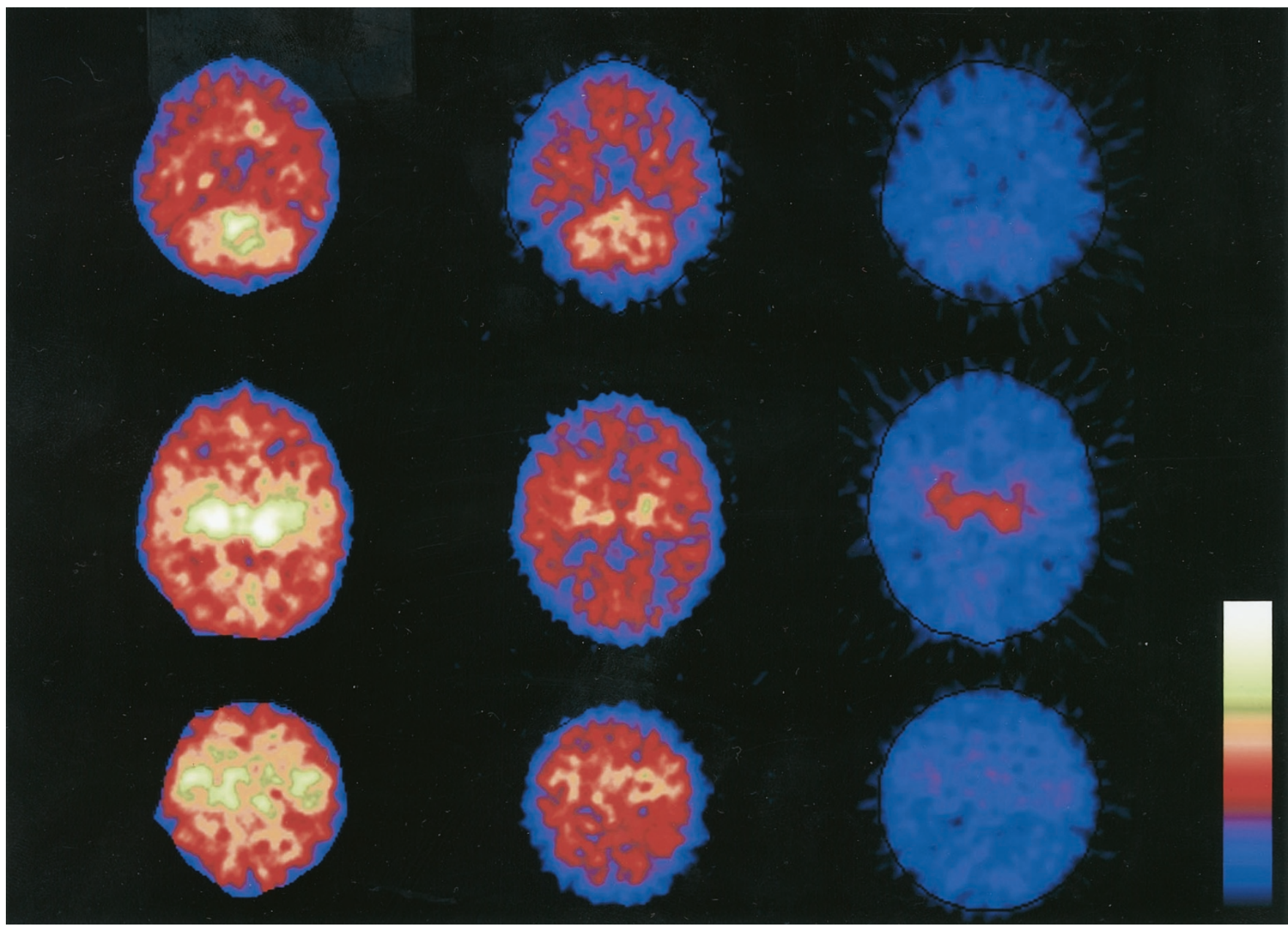

Figure 2. CMRgl measured in the subacute period (10-11 d) after birth asphyxia in three infants with different degrees of HIE. Regional CMRglc in cerebellum (top), thalamus (middle), and sensorimotor cortex (bottom). The infant to the right (HIE-3) has developed CP (tetraplegia) with complicated seizures. The infant to the left (HIE-1) is healthy (2-y follow-up). The scale of the different images is identical. 


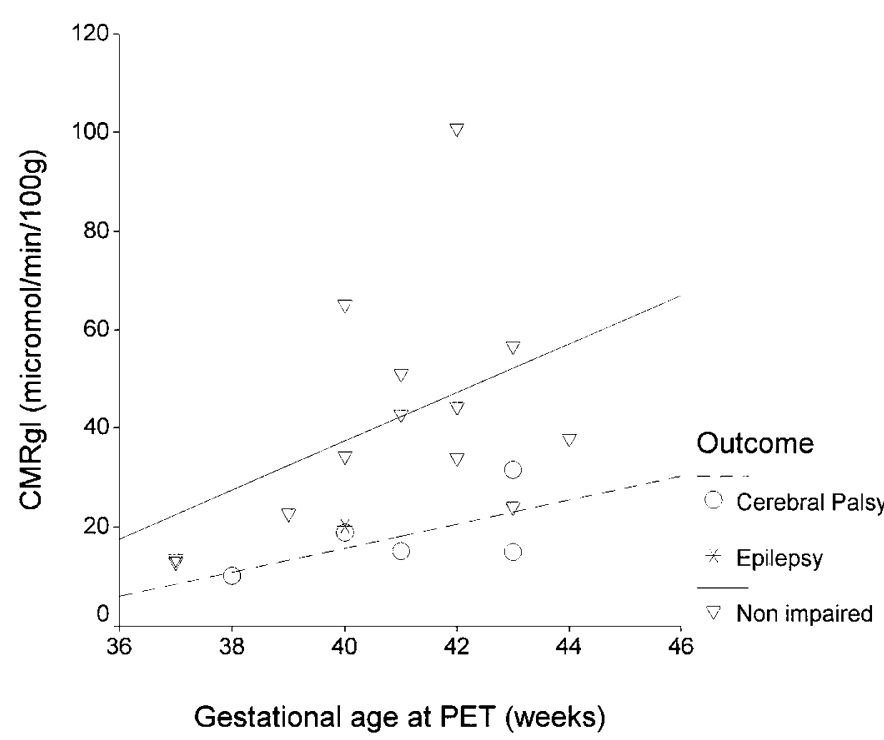

Figure 3. CMRgl measured by PET in term infants with HIE after birth asphyxia, correlated with GA at PET, and outcome. Plots represent the infants and fit lines, the outcome groups.

compare with mean/median (range) 41.5/37.7 (13.0-100.8) $\mu \mathrm{mol} \cdot \mathrm{min}^{-1} \cdot 100 \mathrm{~g}^{-1}$ in the 13 infants with no neurologic sequela at 2 y of age. In one infant with HIE-2 who developed $\mathrm{CP}$, we failed to quantify CMRgl. One infant with moderate HIE who did not develop CP but epilepsy and visual impairment had a CMRgl of $20.2 \mu \mathrm{mol} \cdot \mathrm{min}^{-1} \cdot 100 \mathrm{~g}^{-1}$. In the group of infants with moderate HIE, the three infants who developed CP had CMRgl, mean/median (range) 21.8/18.9 (15.2-31.4), to compare with the seven infants who by $2 \mathrm{y}$ of age have not developed CP or epilepsy, mean/median (range) 29.5/24.0 (13-65) $\mu \mathrm{mol} \cdot \mathrm{min}^{-1} \cdot 100 \mathrm{~g}^{-1}$.

The relative glucose metabolism in the frontal motor area $(\%$ in the frontal motor area of total CMRgl) was significantly correlated with the motor activity scored by video registration in 14 of the infants during the uptake period of FDG $(p<$ 0.02 ). The volume of the frontal motor area was $6 \%$ (SD 3 ) of the total brain volume and did not significantly influence the global CMRgl. The absolute regional glucose metabolism in this frontal motor area was not significantly correlated with the independent motor-activity score $(p=0.19)$.

\section{DISCUSSION}

The main result of this study was the highly significant correlation of CMRgl, measured during the subacute phase after perinatal asphyxia in term infants, with the degree of HIE. The more severe the degree of HIE, the lower was the total CMRgl (Fig. 1). Our findings (Fig. 2) that the deep subcortical parts, thalamus and basal ganglia, and the sensorimotor cortex, all phylogenetically old structures of the brain, were the most metabolically active in newborn infants are consistent with previous observations by Chugani and Phelps (39).

We found a global decrease of CMRgl in infants with moderate and severe HIE compared with infants with mild HIE. However, the subcortical regions still had the relatively highest metabolism also in the sickest infants (see Fig. 2). The
ROI set we used was developed for adults and accordingly was not optimal for infants. The main difference in proportion between infant and adult brain is the location of the border between the frontal and parietal lobes. Because the CMRgl in the frontal and parietal areas were uniform and approximately equal with the exception of the Rolandic areas, which were analyzed separately, the error in location of the border between lobes presumably had little effect on the results. Due to the limited precision of the ROI analysis, we do not attempt to draw any conclusion of the CMRgl in subdivision of the main brain lobes such as the vascular border areas, as has been done for cerebral blood flow, using PET with ${ }^{15} \mathrm{O}-\mathrm{H}_{2} \mathrm{O}$ (17).

All infants with mild HIE had high values of CMRgl and did not develop CP. Infants who developed CP had moderate or severe HIE and decreased CMRgl. One of the three infants with moderate HIE who had low CMRgl $\left(20.2 \mu \mathrm{mol} \cdot \mathrm{min}^{-1} \cdot 100\right.$ $\mathrm{g}^{-1}$ ) but no CP developed seizures and visual impairment. The combination of relatively early gestation and severe illness with need of medication and ventilator due to pulmonary complications could explain the very low metabolism in the two infants with moderate HIE who have not developed CP by $2 \mathrm{y}$ of age (CMRgl, 13.0 and $13.6 \mu \mathrm{mol} \cdot \mathrm{min}^{-1} \cdot 100 \mathrm{~g}^{-1}$, respectively).

Three infants, all in HIE grade 2 and 3, were on antiepileptic drugs on the day of PET, and all developed CP. One with the highest value of CMRgl $\left(31 \mu \mathrm{mol} \cdot \mathrm{min}^{-1} \cdot 100 \mathrm{~g}^{-1}\right)$ among infants with CP had phenytoin. Two infants with CMRgl 10 and $15 \mu \mathrm{mol} \cdot \mathrm{min}^{-1} \cdot 100 \mathrm{~g}^{-1}$, respectively, had phenobarbital. The doses of phenobarbital given in the infants were much lower than in the animal studies in which they were shown to decrease CMRgl and, therefore, are unlikely to have caused a major depression of CMRgl, although studies using PET on patients with phenobarbital as epilepsy treatment (40) showed an increase in brain glucose metabolism after withdrawal of barbiturates.

Most investigators have not been able to quantify CMRgl in newborn infants due to the large number of blood samples the method requires $(20,21)$. The common way to describe CMRgl in infants has, therefore, been to look at relative values. Ratios to the cerebellum and thalamus have been used (39). A Canadian group, who made the first FDG-PET in newborns, used visual inspection (18) and ratios to average cortical activity and cortex/white matter ratios (19). Our quantitative results with decreased metabolic rate of glucose in the whole brain, even in the deep subcortical parts, thalamus, basal ganglia, and cerebellum after asphyxia, suggest that some regions could falsely be interpreted as hypermetabolic when using a method employing relative values only. Consequently, to be able to discuss hypo- and hypermetabolism in different regions of the brain, the absolute values for CMRgl have to be known.

Only a few investigators have used the Sokoloff-Phelps quantification method in children $(22,23)$. Other investigators have used the Patlak method combined with measuring the FDG content over the heart (25), which requires only a few blood samples but necessitates a body scanner.

We also calculated the semiquantitative method SUV, which previously has been used for evaluation of newborn infants (24). When using SUV, it is important to also take the Bglc into 
account (36). SUV multiplied by the Bglc gave a good accuracy of CMRgl in our study.

There are indications that early after hypoxia-ischemia (HI), there may be an increase in CMRgl. Experimental studies using the Vannucci et al. (41) model of neonatal rats have shown an increase in CMRgl 3-12 h after HI (42). In five term infants with HIE investigated by PET 2-3 d after asphyxia, CMRgl was increased, especially in the basal ganglia, in infants with a poor neurologic outcome (23). Hypermetabolism can also be caused by seizures when measured during the ictal phase (43). None of the infants in our study had seizures on the day of the PET scan.

The absolute values of CMRgl, especially in the lessaffected infants with mild HIE, were higher in our study than in previously published studies $(22,23,44)$. Infants with mild HIE, who usually develop normally (8), had a median value of total CMRgl of $48 \mu \mathrm{mol} \cdot \mathrm{min}^{-1} \cdot 100 \mathrm{~g}^{-1}$ (range, 38-101) (Fig. 1). These infants are the closest we can get to normal controls as, for ethical reasons, normal infants could not be investigated. The new method we used for quantification is only validated in adults (26). We cannot exclude the possibility of some instability in the method due to the small amount of blood $(1 \mathrm{~mL})$ we used. Another factor that could influence the results is the LC used for correction between glucose and deoxyglucose. The LC we used is set to be 0.52 for adult normal brain tissue $(35,45)$. Developing brains of infants may have another LC and, in addition, LC for ischemic and partly necrotic tissue can also be different (46). The Bglc may also have some influence on the LC. Also, minor changes in the LC could affect the finally calculated CMRgl.

There are, however, reasons to believe that the high values of CMRgl in the normally developing infants are correct. All infants were examined without any sedation, which is in contrast with other studies $(22,23,47)$. Furthermore, at GA of $37-44 \mathrm{wk}$, when our study was performed, there is a very rapid speed in brain growth and myelination, which requires high metabolism (48). Infants have, as in our study, the highest metabolism in subcortical structures, in the thalamus, basal ganglia, and in the white matter, in contrast with adults in whom the cortical areas have the highest metabolism (22). Recently, an abrupt 5-fold increase in the volume of myelinated white matter in the brain between 35 and 41 wk of gestation has been documented with three-dimensional MRI (49).

A study from Finland showed that total CMRgl in infants (GA, 35-60 wk) increases with maturation and correlates with postconceptional age (44). The only study of CMRgl in preterm infants showed very low values $\left(7.4-11.4 \mu \mathrm{mol} \cdot \mathrm{min}^{-1} \cdot 100 \mathrm{~g}^{-1}\right)$ at 4-7 d in five infants of GA 25-34 wk (47). Even within the short interval over which our study was performed (37-44 wk), we could see an increase of CMRgl with GA at PET. The increase of CMRgl with GA was apparent in both groups of outcome, the impaired and the unimpaired (Fig. 3). These findings show that CMRgl in newborn infants increases with maturation and that the GA has to be taken into account when interpreting the results.

We analyzed the state of alertness and motor activity of the infants during the uptake period of FDG to determine whether there was any influence of the activity on the glucose uptake in the brain. We found no significant correlation of the activity score with the absolute glucose utilization in the Rolandic areas but with the relative glucose uptake. However, this part constitutes only $6 \%$ of the total brain volume and could possibly only marginally influence the total CMRgl.

In the future, specific therapy to reduce the cerebral injury of HI may be possible $(9,10)$. To prognosticate the impairment after perinatal asphyxia and estimate the cerebral lesion (1), early investigation of the brain is essential. It is, therefore, very important to identify the infants who are at the highest risk of being neurologically impaired. The PET technique gives further insight into the cerebral metabolism after asphyxia and could perhaps even be a complement to other methods (50) in the prognostication of neurologic handicap in neonates with HIE after perinatal asphyxia. However, PET is a rather expensive technique and not easily available. The absorbed dose of radiation the infant receives from FDG is rather small and comparable with the radiation from a CT scan of the brain.

The great advantage of the PET technique is the acquisition of functional information, in contrast with MRI $(12,13)$, which only gives morphologic information. PET gives information on the active brain, and the results are not blurred by any sedation. In combination with magnetic resonance spectroscopy $(14,15)$ and diffusion-weighted MRI (51), other functional modalities available at some hospitals today, PET can be an important complement in investigating the function of the brain after HI.

Acknowledgments. The authors thank Kristina Håkansson and the other nurses at the Neonatal Intensive Care Unit for excellent assistance during the PET scans. We also thank Professor Karel Marsal and Dr. Lena Hellström-Westas for valuable comments on the manuscript.

\section{REFERENCES}

1. Volpe JJ 1994 Neurology of the Newborn, 3rd Ed. WB Saunders, Philadelphia, pp 279-313

2. Levene ML, Kornberg J, Williams TH 1985 The incidence and severity of postasphyxial encephalopathy in full- term infants. Early Hum Dev 11:21-26

3. Palme-Killander C 1992 Methods of resuscitation in low Apgar score newborn infants - a national survey. Acta Paediatr Scand 81:739-744

4. Thornberg E, Thiringer K, Odeback A, Milsom I 1995 Birth asphyxia: incidence, clinical course, and outcome in a Swedish population. Acta Paediatr 84:927-932

5. Sarnat HB, Sarnat MS 1976 Neonatal encephalopathy following fetal distress. A clinical and electroencephalographic study. Arch Neurol 33:696-705

6. Finer NN, Robertson CM, Richards RT, Pinnell LE, Peters KL 1981 Hypoxicischemic encephalopathy in term neonates: perinatal factors and outcome. J Pediatr 98:112-117

7. Levene MI, Sands C, Grindulis H, Moore JR 1986 Comparison of two methods of predicting outcome in perinatal asphyxia. Lancet 1:67-69

8. Robertson CM, Finer NN 1993 Long-term follow-up of term neonates with perinatal asphyxia. Clin Perinatol 20:483-500

9. Vannucci RC, Perlman JM 1997 Interventions for perinatal hypoxic-ischemic encephalopathy. Pediatrics 100:1004-1014

10. Wyatt JS, Thoresen M 1997 Hypothermia treatment and the newborn. Pediatrics 100:1028-1030

11. Flodmark O 1988 Perinatal asphyxia: role of imaging techniques to demonstrate neuropathology. Can Med Assoc J (suppl):21-27

12. Barkovich AJ, Westmark K, Partridge C, Sola A, Ferriero DM 1995 Perinata asphyxia: MR findings in the first 10 days. AJNR Am J Neuroradiol 16:427-438

13. Rutherford MA, Pennock JM, Counsell SJ, Mercuri E, Cowan FM, Dubowitz LMS, Edwards AD 1998 Abnormal magnetic resonance signal in the internal capsule predicts poor neurodevelopmental outcome in infants with hypoxic-ischemic encephalopathy. Pediatrics 102:323-328

14. Hope PL, Costello AM, Cady EB, Delpy DT, Tofts PS, Chu A, Hamilton PA, Reynolds EO, Wilkie DR 1984 Cerebral energy metabolism studied with phosphorus NMR spectroscopy in normal and birth-asphyxiated infants. Lancet 2:366-370 
15. Hanrahan JD, Sargentoni J, Azzopardi D, Manji K, Cowan FM, Rutherford MA, Cox IJ, Bell JD, Bryant DJ, Edwards AD 1996 Cerebral metabolism within 18 hours of birth asphyxia: a proton magnetic resonance spectroscopy study. Pediatr Res 39:584590

16. Siesjo BK 1978 Brain Energy Metabolism. John Wiley \& Sons, New York, pp 453-522

17. Volpe JJ, Herscovitch P, Perlman JM, Kreusser KL, Raichle ME 1985 Positron emission tomography in the asphyxiated term newborn: parasagittal impairment of cerebral blood flow. Ann Neurol 17:287-296

18. Doyle LW, Nahmias C, Firnau G, Kenyon DB, Garnett ES, Sinclair JC 1983 Regiona cerebral glucose metabolism of newborn infants measured by positron emission tomography. Dev Med Child Neurol 25:143-151

19. Thorp PS, Levin SD, Garnett ES, Nahmias C, Firnau G, Toi A, Upton AR, Nobbs PT, Sinclair JC 1988 Patterns of cerebral glucose metabolism using 18FDG and positron tomography in the neurologic investigation of the full-term newborn infant. Neuropediatrics 19:146-153

20. Phelps ME, Huang SC, Hoffman EJ, Selin C, Sokoloff L, Kuhl DE 1979 Tomographic measurement of local cerebral glucose metabolic rate in humans with (F-18)2-fluoro2-deoxy-D-glucose: validation of method. Ann Neurol 6:371-388

21. Sokoloff L, Reivich M, Kennedy C, Des Rosiers MH, Patlak CS, Pettigrew KD, Sakurada O, Shinohara M 1977 The [14C]deoxyglucose method for the measurement of local cerebral glucose utilization: theory, procedure, and normal values in the conscious and anesthetized albino rat. J Neurochem 28:897-916

22. Chugani HT, Phelps ME, Mazziotta JC 1987 Positron emission tomography study of human brain functional development. Ann Neurol 22:487-497

23. Blennow M, Ingvar M, Lagercrantz H, Stone-Elander S, Eriksson L, Forssberg H, Ericson K, Flodmark O 1995 Early [18F]FDG positron emission tomography in infants with hypoxic-ischaemic encephalopathy shows hypermetabolism during the postasphyctic period. Acta Paediatr 84:1289-1295

24. Suhonen-Polvi H, Kero P, Korvenranta H, Ruotsalainen U, Haaparanta M, Bergman J, Simell O, Wegelius U 1993 Repeated fluorodeoxyglucose positron emission tomography of the brain in infants with suspected hypoxic-ischaemic brain injury. Eur J Nucl Med 20:759-765

25. Suhonen-Polvi H, Ruotsalainen U, Kinnala A, Bergman J, Haaparanta M, Teras M, P Maa, Solin O, Wegelius U 1995 FDG-PET in early infancy: simplified quantification methods to measure cerebral glucose utilization. J Nucl Med 36:1249-1254

26. Sandell A, Ohlsson T, Erlandsson K, Strand SE 1998 An alternative method to normalize clinical FDG studies. J Nucl Med 39:552-555

27. Marsal K, Persson PH, Larsen T, Lilja H, Selbing A, Sultan B 1996 Intrauterine growth curves based on ultrasonically estimated foetal weights. Acta Paediatr 85:843-848

28. Prechtl HF 1974 The behavioural states of the newborn infant (a review). Brain Res 76:185-212

29. Litton J, Bergstrom M, Eriksson L, Bohm C, Blomqvist G, Kesselberg M 1984 Performance study of the PC-384 positron camera system for emission tomography of the brain. J Comput Assist Tomogr 8:74-87

30. Bergstrom M, Eriksson L, Bohm C, Blomqvist G, Litton J 1983 Correction for scattered radiation in a ring detector positron camera by integral transformation of the projections. J Comput Assist Tomogr 7:42-50

31. Bergstrom M, Litton J, Eriksson L, Bohm C, Blomqvist G 1982 Determination of object contour from projections for attenuation correction in cranial positron emission tomography. J Comput Assist Tomogr 6:365-372

32. Toorangian S, Mulholland G, Jewett D, Bachelor M, Kilbourn M 1990 Routine production of 2-deoxy-2(18F)fluoro-D-glucose by direct nucleophilic exchange on a quaternary ammonium resin. Nucl Med Biol 17:273-279

33. Ohlsson T, Sandell A, Hellborg R, Håkansson K, Nilsson C, Strand SE 1996 Clinical useful quantities of $(18 \mathrm{~F})$ fluoride produced by $6 \mathrm{MeV}$ proton irradiation of a $\mathrm{H} 2{ }^{18} \mathrm{O}$ target. Nucl Instr Methods Phys Res 379:A341-A342
34. Rhodes CG, Wise RJ, Gibbs JM, Frackowiak RS, Hatazawa J, Palmer AJ, Thomas DG, Jones T 1983 In vivo disturbance of the oxidative metabolism of glucose in human cerebral gliomas. Ann Neurol 14:614-626

35. Reivich M, Alavi A, Wolf A, Fowler J, Russell J, Arnett C, MacGregor RR, Shiue CY, Atkins H, Anand A, Dann R, Greenberg JH 1985 Glucose metabolic rate kinetic model parameter determination in humans: the lumped constants and rate constants for $[18 \mathrm{~F}]$ fluorodeoxyglucose and $[11 \mathrm{C}]$ deoxyglucose. J Cereb Blood Flow Metab 5:179-192

36. Langen KJ, Braun U, Rota Kops E, Herzog H, Kuwert T, Nebeling B, Feinendegen LE 1993 The influence of plasma glucose levels on fluorine-18- fluorodeoxyglucose uptake in bronchial carcinomas. J Nucl Med 34:355-359

37. Gallagher BM, Ansari A, Atkins H, Casella V, Christman DR, Fowler JS, Ido T, MacGregor RR, Som P, Wan CN, Wolf AP, Kuhl DE, Reivich M 1977 Radiopharmaceuticals XXVII. 18F-labeled 2-deoxy-2-fluoro-d-glucose as a radiopharmaceutical for measuring regional myocardial glucose metabolism in vivo: tissue distribution and imaging studies in animals. J Nucl Med 18:990-996

38. Kretschmann HJ, Weirinich W 1986 Neuroanatomy and Cranial Computed Tomography. Thieme Verlag, Stuttgart

39. Chugani HT, Phelps ME 1986 Maturational changes in cerebral function in infants determined by 18FDG positron emission tomography. Science 231:840-843

40. Theodore WH, DiChiro G, Margolin R, Fishbein D, Porter RJ, Brooks RA 1986 Barbiturates reduce human cerebral glucose metabolism. Neurology 36:60-64

41. Vannucci RC, Yager JY, Vannucci SJ 1994 Cerebral glucose and energy utilization during the evolution of hypoxic-ischemic brain damage in the immature rat. J Cereb Blood Flow Metab 14:279-288

42. Gilland E, Bona E, Hagberg H 1998 Temporal changes of regional glucose use, blood flow, and microtubule-associated protein-2 immunostaining after hypoxia-ischemia in the immature rat brain. J Cereb Blood Flow Metab 18:222-228

43. Chugani HT, Rintahaka PJ, Shewmon DA 1994 Ictal patterns of cerebral glucose utilization in children with epilepsy. Epilepsia 35:813-822

44. Kinnala A, Suhonen-Polvi H, Aarimaa T, Kero P, Korvenranta H, Ruotsalainen U, Bergman J, Haaparanta M, Solin O, Nuutila P, Wegelius U 1996 Cerebral metabolic rate for glucose during the first six months of life: an FDG positron emission tomography study. Arch Dis Child Fetal Neonatal Ed 74:F153-F157

45. Gjedde A, Kuwabara H, Evans AC 1990 Metabolic brain imaging. Direct regional measurement of transfer coefficients and lumped constant. Acta Radiol Suppl $374: 117-121$

46. Gjedde A, Wienhard K, Heiss WD, Kloster G, Diemer NH, Herholz K, Pawlik G 1985 Comparative regional analysis of 2-fluorodeoxyglucose and methylglucose uptake in brain of four stroke patients. With special reference to the regional estimation of the lumped constant. J Cereb Blood Flow Metab 5:163-178

47. Powers WJ, Rosenbaum JL, Dence CS, Markham J, Videen TO 1998 Cerebral glucose transport and metabolism in preterm human infants. J Cereb Blood Flow Metab 18:632-638

48. Dobbing J, Sands J 1978 Head circumference, biparietal diameter, and brain growth in fetal and postnatal life. Early Hum Dev 2:81-87

49. Huppi PS, Warfield S, Kikinis R, Barnes PD, Zientara GP, Jolesz FA, Tsuji MK, Volpe JJ 1998 Quantitative magnetic resonance imaging of brain development in premature and mature newborns. Ann Neurol 43:224-235

50. Hellstrom-Westas L, Rosen I, Svenningsen NW 1995 Predictive value of early continuous amplitude integrated EEG recordings on outcome after severe birth asphyxia in full-term infants. Arch Dis Child Fetal Neonatal Ed 72:F34-F38

51. Cowan FM, Pennock JM, Hanrahan JD, Manji KP, Edwards AD 1994 Early detection of cerebral infarction and hypoxic ischemic encephalopathy in neonates using diffusion-weighted magnetic resonance imaging. Neuropediatrics 25:172-175 